\title{
Cytokines, Inflammation and Pain
}

\author{
Jun-Ming Zhang, MSc, MD ${ }^{1}$ and Jianxiong An, MSc, MD ${ }^{2}$ \\ ${ }^{1}$ Department of Anesthesiology, University of Cincinnati, 231 Albert Sabin Way, Cincinnati, Ohio, \\ 45267-0531 \\ ${ }^{2}$ Department of Anesthesiology and Pain Medicine, Tsinghua University Yuquan Hospital, \#5 \\ ShiJingShan Road, Beijing, 100049, China
}

\begin{abstract}
Cytokines are small secreted proteins released by cells have a specific effect on the interactions and communications between cells. Cytokine is a general name; other names include lymphokine (cytokines made by lymphocytes), monokine (cytokines made by monocytes), chemokine (cytokines with chemotactic activities), and interleukin (cytokines made by one leukocyte and acting on other leukocytes). Cytokines may act on the cells that secrete them (autocrine action), on nearby cells (paracrine action), or in some instances on distant cells (endocrine action). There are both proinflammatory cytokines and anti-inflammatory cytokines. There is significant evidence showing that certain cytokines/chemokines are involved in not only the initiation but also the persistence of pathologic pain by directly activating nociceptive sensory neurons. Certain inflammatory cytokines are also involved in nerve-injury/inflammation-induced central sensitization, and are related to the development of contralateral hyperalgesia/allodynia. The discussion presented in this chapter describes several key pro-inflammatory cytokines/chemokines and anti-inflammatory cytokines, their relation with pathological pain in animals and human patients, and possible underlying mechanisms.
\end{abstract}

\section{Keywords}

cytokine; inflammation; pain; hyperalgesia

\section{Introduction}

Inflammatory responses in the peripheral and central nervous systems play key roles in the development and persistence of many pathological pain states [1]. Certain inflammatory cytokines in spinal cord, dorsal root ganglion (DRG), injured nerve or skin are known to be associated with pain behaviors and with the generation of abnormal spontaneous activity from injured nerve fibers or compressed/inflamed DRG neurons.

Cytokines are small secreted proteins released by cells have a specific effect on the interactions and communications between cells. Cytokine is a general name; other names include lymphokine (cytokines made by lymphocytes), monokine (cytokines made by monocytes), chemokine (cytokines with chemotactic activities), and interleukin (cytokines made by one leukocyte and acting on other leukocytes). Cytokines may act on the cells that secrete them (autocrine action), on nearby cells (paracrine action), or in some instances on distant cells (endocrine action).

Please send correspondence to: Jun-Ming Zhang, MSc, MD, Department of Anesthesiology, University of Cincinnati College of Medicine, 231 Albert Sabin Way, Cincinnati, OH, 45267-0531, Tel: 513-558-2427, Fax: 513-558-0995, Jun-Ming.Zhang@uc.edu. 
It is common for different cell types to secrete the same cytokine or for a single cytokine to act on several different cell types (pleiotropy). Cytokines are redundant in their activity, meaning similar functions can be stimulated by different cytokines. They are often produced in a cascade, as one cytokine stimulates its target cells to make additional cytokines. Cytokines can also act synergistically or antagonistically (Figure 1).

Cytokines are made by many cell populations, but the predominant producers are helper $\mathrm{T}$ cells (Th) and macrophages. Cytokines may be produced in and by peripheral nerve tissue during physiological and pathological processes by resident and recruited macrophages, mast cells, endothelial cells, and Schwann cells. Following a peripheral nerve injury, macrophages and Schwann cells that gather around the injured site of the nerve secrete cytokines and specific growth factors required for nerve regeneration. Localized inflammatory irritation of the dorsal root ganglion (DRG) not only increases pro-inflammatory cytokines but also decreases antiinflammatory cytokines [2]. Cytokines can also be synthesized and released from the herniated nucleus pulposus, synthesized inside the spinal cord [3], the DRG soma [4], or the inflamed skin [5]. Furthermore, cytokines may be transported in a retrograde fashion from the periphery, via axonal or non-axonal mechanisms, to the DRG and dorsal horn, where they can have profound effects on neuronal activity [6] and therefore contribute to the etiology of various pathological pain states.

\section{Cytokines and pain}

\section{Pro-inflammatory cytokines}

Proinflammatory cytokines are produced predominantly by activated macrophages and are involved in the up-regulation of inflammatory reactions. There is abundant evidence that certain pro-inflammatory cytokines such as IL- $1 \beta, \mathrm{IL}-6$, and TNF- $\alpha$ are involved in the process of pathological pain.

IL- $1 \beta$ is released primarily by monocytes and macrophages as well as by nonimmune cells, such as fibroblasts and endothelial cells, during cell injury, infection, invasion, and inflammation. Very recently, it was found that IL- $1 \beta$ is expressed in nociceptive DRG neurons [7]. IL-1 $\beta$ expression is enhanced following crush injury to peripheral nerve and after trauma in microglia and astrocytes in the central nervous system (CNS) [8]. IL-1 $\beta$ can produce hyperalgesia following either intraperitoneal, intracerebroventricular or intraplantar injection $[9,10]$. Moreover, IL-1 $\beta$ was found to increase the production of substance $P$ and prostaglandin $\mathrm{E}_{2}\left(\mathrm{PGE}_{2}\right)$ in a number of neuronal and glial cells [11,12]. IL-1 ra, a specific IL-1 receptor antagonist, competitively binds to the same receptor as IL- $1 \beta$ but does not transduce a cellular signal, thereby blocking IL- $1 \beta$-mediated cellular changes. Administrations of IL-1ra and other anti-inflammatory cytokines have been demonstrated to prevent or attenuate cytokinemediated inflammatory hyperalgesia [13] and nerve-injury induced mechanical allodynia [14].

IL-6 has been shown to play a central role in the neuronal reaction to nerve injury. Suppression of IL-6R by in vivo application of anti-IL-6R antibodies led to reduced regenerative effects [15]. IL-6 is also involved in microglial and astrocytic activation as well as in regulation of neuronal neuropeptides expression [16]. There is evidence that IL-6 contributes to the development of neuropathic pain behavior following a peripheral nerve injury $[17,18]$. For example, sciatic cryoneurolysis, a sympathetically-independent model of neuropathic pain involving repeatedly freezing and thawing a section of the sciatic nerve, results in increased IL-6 immunoreactivity in the spinal cord [3]. In addition, intrathecal infusion of IL-6 induces tactile allodynia and thermal hyperalgesia in intact and nerve-injured rats, respectively. 
TNF- $\alpha$, also known as cachectin, is another inflammatory cytokine that plays a wellestablished, key role in some pain models. TNF acts on several different signaling pathways through two cell surface receptors, TNFR1 and TNFR2 to regulate apoptotic pathways, NF$\mathrm{kB}$ activation of inflammation, and activate stress-activated protein kinases (SAPKs). TNF- $\alpha$ receptors are present in both neurons and glia [19]. TNF- $\alpha$ has been shown to play important roles in both inflammatory and neuropathic hyperalgesia. Intraplantar injection of complete Freund's adjuvant in adult rats resulted in significant elevation in the levels of TNF- $\alpha$, IL-1 $\beta$, and nerve growth factor (NGF) in the inflamed paw. A single injection of anti-TNF- $\alpha$ antiserum before the CFA significantly delayed the onset of the resultant inflammatory hyperalgesia and reduced IL-1 $\beta$ but not NGF levels [20]. Intraplantar injection of TNF- $\alpha$ also produces mechanical [21] and thermal hyperalgesia [10]. It has been found that TNF- $\alpha$ injected into nerves induces Wallerian degeneration [20,22] and generates the transient display of behaviors and endoneurial pathologies found in experimentally painful nerve injury [23]. TNF binding protein (TNF-BP), an inhibitor of TNF, is a soluble form of a transmembrane TNF-receptor. When TNF-BP is administered systemically, the hyperalgesia normally observed after lipopolysaccharide (LPS) administration is completely eliminated [9]. Intrathecal administration of a combination of TNF-BP and IL-1 antagonist attenuated mechanical allodynia in rats with $\mathrm{L}_{5}$ spinal nerve transection [24].

\section{Chemokines}

A variety of cytokines are known to induce chemotaxis. One particular subgroup of structurally related cytokines is known as chemokines. The term chemotactic cytokines (CHEMOtactic CytoKINES) usually refers to this. These factors represent a family of low molecular weight secreted proteins that primarily function in the activation and migration of leukocytes although some of them also possess a variety of other functions. Chemokines have conserved cysteine residues that allow them to be assigned to four groups: $\mathrm{C}-\mathrm{C}$ chemokines (RANTES, monocyte chemoattractant protein or MCP-1, monocyte inflammatory protein or MIP-1 $\alpha$, and MIP-1 $\beta$ ), C-X-C chemokines (IL-8 also called growth related oncogene or GRO/KC), C chemokines (lymphotactin), and CXXXC chemokines (fractalkine).

Various chemokines including MIP- $1 \alpha, \mathrm{MCP}-1$ and GRO/KC are up-regulated not only in models of neuroinflammatory $[2,25]$ and demylinating diseases, but also in various forms of CNS trauma [26] and in injured peripheral nerve [27]. Receptors for MCP-1, MIP-1 $\alpha$ and GRO/ $\mathrm{KC}$ are expressed on DRG neurons [28]. Interestingly, mice lacking the CCR2 receptor completely fail to develop mechanical allodynia in the partial sciatic injury model although pain sensitivity in uninjured animals is normal. In the same study, normal mice showed a sustained upregulation of the receptors in both DRG and peripheral nerve after the injury [29]. This suggests that the chemokines, including MCP-1 in particular, play very key roles in neuropathic pain as well as in neuroinflammatory conditions.

\section{Anti-inflammatory cytokines}

The anti-inflammatory cytokines are a series of immunoregulatory molecules that control the pro-inflammatory cytokine response. Cytokines act in concert with specific cytokine inhibitors and soluble cytokine receptors to regulate the human immune response. Their physiologic role in inflammation and pathologic role in systemic inflammatory states are increasingly recognized. Major anti-inflammatory cytokines include interleukin (IL)-1 receptor antagonist, IL-4, IL-10, IL-11, and IL-13. Leukemia inhibitory factor, interferon-alpha, IL-6, and transforming growth factor (TGF)- $\beta$ are categorized as either anti-inflammatory or proinflammatory cytokines, under various circumstances. Specific cytokine receptors for IL-1, TNF- $\alpha$, and IL-18 also function as inhibitors for pro-inflammatory cytokines. 
Among all the anti-inflammatory cytokines, IL-10 is a cytokine with potent anti-inflammatory properties, repressing the expression of inflammatory cytokines such as TNF- $\alpha$, IL- 6 and IL-1 by activated macrophages. In addition, IL-10 can up-regulate endogenous anti-cytokines and down-regulate pro-inflammatory cytokine receptors. Thus, it can counter-regulate production and function of pro-inflammatory cytokines at multiple levels. Acute administration of IL-10 protein has been well-documented to suppress the development of spinally-mediated pain facilitation in diverse animal models such as peripheral neuritis, spinal cord excitotoxic injury, and peripheral nerve injury [30]. Blocking spinal IL-10, on the other hand, has been found to prevent and even reverse established neuropathic pain behaviors [31]. Recent clinical studies also indicate that low blood levels of IL-10 and another anti-inflammatory cytokine, IL-4, could be key to chronic pain since low concentrations of these two cytokines were found in patients with chronic widespread pain [32].

The family of TGF- $\beta$ comprises 5 different isoforms (TGF- $\beta 1$ to $-\beta 5$ ). TGF- $\beta 1$ is found in meninges, choroid plexus, and peripheral ganglia and nerves [33]. It is known that TGF- $\beta$ suppresses cytokine production by inhibiting macrophage and Th1 cell activity; counteracts IL-1, IL-2, IL-6, and TNF; and induces IL-1 ra 6 [34]. Its mRNA is induced following axotomy and may be involved in a negative-feedback loop to limit the extent of glial activation [35]. TGF- $\beta 1$ also antagonizes nitric oxide production in macrophages [36]. Nitric oxide has been strongly implicated in the final common pathway of neuropathic pain [37]. It is expected that by its anti-cytokine action, TGF- $\beta 1$ or agents that induce its activity may be effective therapy for neuropathic pain.

\section{Glial activation in CNS and PNS}

In the CNS, there are two types of glial cells, microglia and astrocytes, which can be activated by excitatory neurotransmitters released from nearby neurons. These neurotransmitters include EAA, SP, PGEs, adenosine triphosphate (ATP), and nitric oxide. A novel neuron to glia signal is fractalkine, a protein expressed on the extracellular surface of neurons [38]. Fractalkine is tethered to the neuronal membrane by a mucin stalk. When the neuron is sufficiently activated, the stalk breaks, releasing fractalkine into the extracellular fluid. As immunocompetent cells, activated glia release several key pro-inflammatory cytokines, including TNF- $\alpha$, IL- $1 \beta$, and IL-6 $[39,40]$.

It has been well demonstrated that spinal glial activation is necessary for induction of the neuropathic pain state $[30,41,42]$. Spinal administration of glial activator, fractalkine, induces cutaneous hyperalgesia, whereas spinal administration of a fractalkine receptor antagonist blocks neuropathic pain [1]. Furthermore, blocking the activation of spinal cord glia with the inhibitor fluorocitrate blocks the pathological pain state in rats with peripheral sciatic nerve neuritis [42]. Recently, it was found that administration of a new glia-specific inhibitor, minocycline, blocked the development of neuropathic pain. Minocycline, a lipid-soluble tetracycline derivative with anti-inflammatory effects, inhibits an IL-1 $\beta$-converting enzyme and inducible nitric oxide synthesis up-regulation. Minocycline also prevents glial cell proliferation and inhibits the activation of p38 MAPK [43].

Non-neuronal cells in the peripheral nervous system also react to nerve injury. In addition to hematogenous macrophage infiltration, the satellite glia that surround the somata of sensory neurons proliferate [44], elaborate processes [45], and become immunoreactive for glial fibrillary acidic protein (GFAP) [46].

\section{Mechanisms underlying cytokines-mediated pathological pain}

There is evidence that pro-inflammatory cytokines (e.g., IL-1 $\beta$, TNF- $\alpha$ ) $[6,47,48]$ and chemokines (e.g., MCP-1) $[25,28,49]$ may directly modulate neuronal activity in various 
classes of neurons in the peripheral and central nervous system. In the peripheral nervous system, abnormal spontaneous activity can be evoked from nociceptive neurons by topical application of TNF- $\alpha$ to the peripheral axons in vivo [48], or to the somata of the DRG neurons in vitro [47]. Large, myelinated fast conducting $\mathrm{A} \beta$ neurons can also be excited by topical application of TNF- $\alpha$ to the DRG [47] or by an autologous HNP extract [50]. TNF- $\alpha$ can enhance the sensitivity of sensory neurons to the excitation produced by capsaicin and this enhancement likely is mediated by the neuronal production of prostaglandins [51]. It was found that TNF- $\alpha$-induced neuronal excitation is mediated by cAMP-dependent protein kinase (PKA) pathway [47]. The p38 mitogen-activated protein kinase (MAPK) is also involved in TNF- $\alpha$ induced cutaneous hypersensitivity to mechanical or thermal stimulation [4]. Results obtained from IL-6 knockout mice indicates that IL-6 plays a facilitating role in sympathetic sprouting induced by nerve injury and that its effect on pain behavior is indirectly mediated through sympathetic sprouting in the DRG [18]. Most recently, it is reported that localized inflammation of the DRG up-regulates a number of pro-inflammatory cytokines including IL-6 and induces abnormal sympathetic sprouting in the absence of peripheral nerve injury [2]. It suggests a possible correlation between inflammatory responses and sympathetic sprouting, which are two well-known mechanisms implicated in various chronic pain states.

In summary, proinflammatory cytokines are involved in the development of inflammatory and neuropathic pain. Just as specific cytokines and their neutralizing antibodies have been introduced into clinical trials for the treatment of stroke, Alzheimer's disease, autoimmune diseases, wound healing, and amyotrophic lateral sclerosis, one could utilize local or systemic delivery of anti-inflammatory cytokines or inflammatory cytokine antagonists for the treatment of chronic pain. These specific cytokines or antagonists would act to disrupt the hyperexcitability cycle taking place in the sensory neurons, providing a new, non-opioid therapeutic approach for the treatment of pathological pain due to inflammation or peripheral nerve injury.

\section{Acknowledgments}

Supported by NIH/NINDS Grant R01NS045594 (J-M Zhang)

\section{References}

1. Watkins LR, Milligan ED, Maier SF. Glial proinflammatory cytokines mediate exaggerated pain states: implications for clinical pain. Adv Exp Med Biol 2003;521:1-21. [PubMed: 12617561]

2. Xie WR, Deng H, Li H, et al. Robust increase of cutaneous sensitivity, cytokine production and sympathetic sprouting in rats with localized inflammatory irritation of the spinal ganglia. Neuroscience 2006;142:809-822. [PubMed: 16887276]

3. DeLeo JA, Colburn RW, Nichols M, et al. Interleukin-6-mediated hyperalgesia/allodynia and increased spinal IL-6 expression in a rat mononeuropathy model. J Interferon Cytokine Res 1996;16:695-700. [PubMed: 8887053]

4. Schafers M, Svensson CI, Sommer C, et al. Tumor necrosis factor-alpha induces mechanical allodynia after spinal nerve ligation by activation of p38 MAPK in primary sensory neurons. J Neurosci 2003;23:2517-2521. [PubMed: 12684435]

5. Heijmans-Antonissen C, Wesseldijk F, Munnikes RJ, et al. Multiplex bead array assay for detection of 25 soluble cytokines in blister fluid of patients with complex regional pain syndrome type 1. Mediators Inflamm 2006;2006:28398. [PubMed: 16864900]

6. Ozaktay AC, Kallakuri S, Takebayashi T, et al. Effects of interleukin-1 beta, interleukin-6, and tumor necrosis factor on sensitivity of dorsal root ganglion and peripheral receptive fields in rats. Eur Spine J 2006:1-9.

7. Copray JC, Mantingh I, Brouwer N, et al. Expression of interleukin-1 beta in rat dorsal root ganglia. J Neuroimmunol 2001;118:203-211. [PubMed: 11498255] 
8. Yan HQ, Banos MA, Herregodts P, et al. Expression of interleukin (IL)-1 beta, IL-6 and their respective receptors in the normal rat brain and after injury. Eur J Immunol 1992;22:2963-2971. [PubMed: 1425920]

9. Watkins LR, Wiertelak EP, Goehler LE, et al. Characterization of cytokine-induced hyperalgesia. Brain Res 1994;654:15-26. [PubMed: 7982088]

10. Perkins MN, Kelly D. Interleukin-1 beta induced-desArg9bradykinin-mediated thermal hyperalgesia in the rat. Neuropharmacology 1994;33:657-660. [PubMed: 7936101]

11. Jeanjean AP, Moussaoui SM, Maloteaux JM, et al. Interleukin-1 beta induces long-term increase of axonally transported opiate receptors and substance P. Neuroscience 1995;68:151-157. [PubMed: 7477920]

12. Schweizer A, Feige U, Fontana A, et al. Interleukin-1 enhances pain reflexes. Mediation through increased prostaglandin E2 levels. Agents \& Actions 1988;25:246-251. [PubMed: 3265268]

13. Maier SF, Wiertelak EP, Martin D, et al. Interleukin-1 mediates the behavioral hyperalgesia produced by lithium chloride and endotoxin. Brain Res 1993;623:321-324. [PubMed: 8221116]

14. Sweitzer S, Martin D, Deleo JA. Intrathecal interleukin-1 receptor antagonist in combination with soluble tumor necrosis factor receptor exhibits an anti-allodynic action in a rat model of neuropathic pain. Neuroscience 2001;103:529-539. [PubMed: 11246166]

15. Hirota H, Kiyama H, Kishimoto T, et al. Accelerated Nerve Regeneration in Mice by upregulated expression of interleukin (IL) 6 and IL-6 receptor after trauma. J Exp Med 1996;183:2627-2634. [PubMed: 8676083]

16. Klein MA, Moller JC, Jones LL, et al. Impaired neuroglial activation in interleukin-6 deficient mice. Glia 1997;19:227-233. [PubMed: 9063729]

17. DeLeo, JA.; Colburn, RW. The role of cytokines in nociception and chronic pain. In: Weinstein, JN.; Gordon, SL., editors. Low Back Pain: A scientific and clinical overview. American Academy of Orthopaedic Surgeons; 1995. p. 163-185.

18. Ramer MS, Murphy PG, Richardson PM, et al. Spinal nerve lesion-induced mechanoallodynia and adrenergic sprouting in sensory ganglia are attenuated in interleukin-6 knockout mice. Pain 1998;78:115-121. [PubMed: 9839821]

19. Boka G, Anglade P, Wallach D, et al. Immunocytochemical analysis of tumor necrosis factor and its receptors in Parkinson's disease. Neuroscience Letters 1994;172:151-154. [PubMed: 8084523]

20. Woolf CJ, Allchorne A, Safieh-Garabedian B, et al. Cytokines, nerve growth factor and inflammatory hyperalgesia: the contribution of tumour necrosis factor alpha. Br J Pharmacol 1997;121:417-424. [PubMed: 9179382]

21. Cunha FQ, Poole S, Lorenzetti BB, et al. The pivotal role of tumour necrosis factor alpha in the development of inflammatory hyperalgesia. Br J Pharmacol 1992;107:660-664. [PubMed: 1472964]

22. Creange A, Barlovatz-Meimon G, Gherardi RK. Cytokines and peripheral nerve disorders. Eur Cytokine Netw 1997;8:145-151. [PubMed: 9262963]

23. Wagner R, Myers RR. Endoneurial injection of TNF-alpha produces neuropathic pain behaviors. Neuroreport 1996;7:2897-2901. [PubMed: 9116205]

24. Sweitzer S, Deleo JA, Martin D. Intrathecal interleukin-1 receptor antagonist and tumor necrosis factor binding protein exhibit an antiallodynic effect in a rat model of neuropathic pain. Soc Neurosci Abstr 1999;25579.4

25. White FA, Sun J, Waters SM, et al. Excitatory monocyte chemoattractant protein-1 signaling is upregulated in sensory neurons after chronic compression of the dorsal root ganglion. Proc Natl Acad Sci U S A 2005;102:14092-14097. [PubMed: 16174730]

26. Berman JW, Guida MP, Warren J, et al. Localization of monocyte chemoattractant peptide-1 expression in the central nervous system in experimental autoimmune encephalomyelitis and trauma in the rat. J Immunol 1996;156:3017-3023. [PubMed: 8609424]

27. Taskinen HS, Roytta M. Increased expression of chemokines (MCP-1, MIP-1alpha, RANTES) after peripheral nerve transection. J Peripher Nerv Syst 2000;5:75-81. [PubMed: 10905466]

28. Oh SB, Tran PB, Gillard SE, et al. Chemokines and glycoprotein 120 produce pain hypersensitivity by directly exciting primary nociceptive neurons. J Neurosci 2001;21:5027-5035. [PubMed: $11438578]$ 
29. Abbadie C, Lindia JA, Cumiskey AM, et al. Impaired neuropathic pain responses in mice lacking the chemokine receptor CCR2. Proc Natl Acad Sci U S A 2003;100:7947-7952. [PubMed: 12808141]

30. Wieseler-Frank J, Maier SF, Watkins LR. Glial activation and pathological pain. Neurochem Int 2004;45:389-395. [PubMed: 15145553]

31. Milligan ED, Sloane EM, Langer SJ, et al. Controlling neuropathic pain by adeno-associated virus driven production of the anti-inflammatory cytokine, interleukin-10. Mol Pain 2005;1:9. [PubMed: 15813997]

32. Uceyler N, Valenza R, Stock M, et al. Reduced levels of antiinflammatory cytokines in patients with chronic widespread pain. Arthritis Rheum 2006;54:2656-2664. [PubMed: 16871547]

33. Unsicker K, Flanders KC, Cissel DS, et al. Transforming growth factor beta isoforms in the adult rat central and peripheral nervous system. Neuroscience 1991;44:613-625. [PubMed: 1754055]

34. Roberts AB, Sporn MB. Physiological actions and clinical applications of transforming growth factorbeta (TGF-beta). Growth Factors 1993;8:1-9. [PubMed: 8448037]

35. Kiefer R, Lindholm D, Kreutzberg GW. Interleukin-6 and transforming growth factor-beta 1 mRNAs are induced in rat facial nucleus following motoneuron axotomy. Eur J Neurosci 1993;5:775-781. [PubMed: 8281289]

36. Ding A, Nathan CF, Graycar J, et al. Macrophage deactivating factor and transforming growth factorsbeta 1 -beta 2 and -beta 3 inhibit induction of macrophage nitrogen oxide synthesis by IFN-gamma. J Immunol 1990;145:940-944. [PubMed: 2115549]

37. Meller ST, Gebhart GF. Nitric oxide (NO) and nociceptive processing in the spinal cord. Pain 1993;52:127-136. [PubMed: 8455960]

38. Chapman GA, Moores K, Harrison D, et al. Fractalkine cleavage from neuronal membranes represents an acute event in the inflammatory response to excitotoxic brain damage. J Neurosci 2000;20:RC87. [PubMed: 10899174]

39. Winkelstein BA, Rutkowski MD, Sweitzer SM, et al. Nerve injury proximal or distal to the DRG induces similar spinal glial activation and selective cytokine expression but differential behavioral responses to pharmacologic treatment. J Comp Neurol 2001;439:127-139. [PubMed: 11596043]

40. Watkins LR, Maier SF. Beyond neurons: Evidence that immune and glial cells contribute to pathological pain states [Review]. Physiological Reviews 2002;82:981-1011. [PubMed: 12270950]

41. DeLeo JA, Rutkowski MD, Stalder AK, et al. Transgenic expression of TNF by astrocytes increases mechanical allodynia in a mouse neuropathy model. Neuroreport 2000;11:599-602. [PubMed: 10718321]

42. Milligan ED, Twining C, Chacur M, et al. Spinal glia and proinflammatory cytokines mediate mirrorimage neuropathic pain in rats. J Neurosci 2003;23:1026-1040. [PubMed: 12574433]

43. Wu DC, Jackson-Lewis V, Vila M, et al. Blockade of microglial activation is neuroprotective in the 1-methyl-4-phenyl-1,2,3,6-tetrahydropyridine mouse model of Parkinson disease. J Neurosci 2002;22:1763-1771. [PubMed: 11880505]

44. Lu X, Richardson PM. Inflammation near the nerve cell body enhances axonal regeneration. J Neurosci 1991;11:972-978. [PubMed: 1901354]

45. Leech RW. Changes in satellite cells of rat dorsal root ganglia during central chromatolysis. An electron microscopic study. Neurology 1967;17:349-358. [PubMed: 6067070]

46. Woodham P, Anderson PN, Nadim W, et al. Satellite cells surrounding axotomised rat dorsal root ganglion cells increase expression of a GFAP-like protein. Neuroscience Letters 1989;98:8-12. [PubMed: 2710403]

47. Zhang J-M, Li HQ, Liu B, et al. Acute topical application of tumor necrosis factor alpha evokes protein kinase A-dependent responses in rat sensory neurons. J Neurophysiol 2002;88:1387-1392. [PubMed: 12205159]

48. Sorkin LS, Xiao WH, Wagner R, et al. Tumour necrosis factor-alpha induces ectopic activity in nociceptive primary afferent fibres. Neuroscience 1997;81:255-262. [PubMed: 9300418]

49. Sun JH, Yang B, Donnelly DF, et al. MCP-1 enhances excitability of nociceptive neurons in chronically compressed dorsal root ganglia. J Neurophysiol. 2006

50. Cavanaugh JM. Neural mechanisms of lumbar pain. Spine 1995;20:1804-1809. [PubMed: 7502138] 
51. Nicol GD, Lopshire JC, Pafford CM. Tumor necrosis factor enhances the capsaicin sensitivity of rat sensory neurons. J Neurosci 1997;17:975-982. [PubMed: 8994052] 


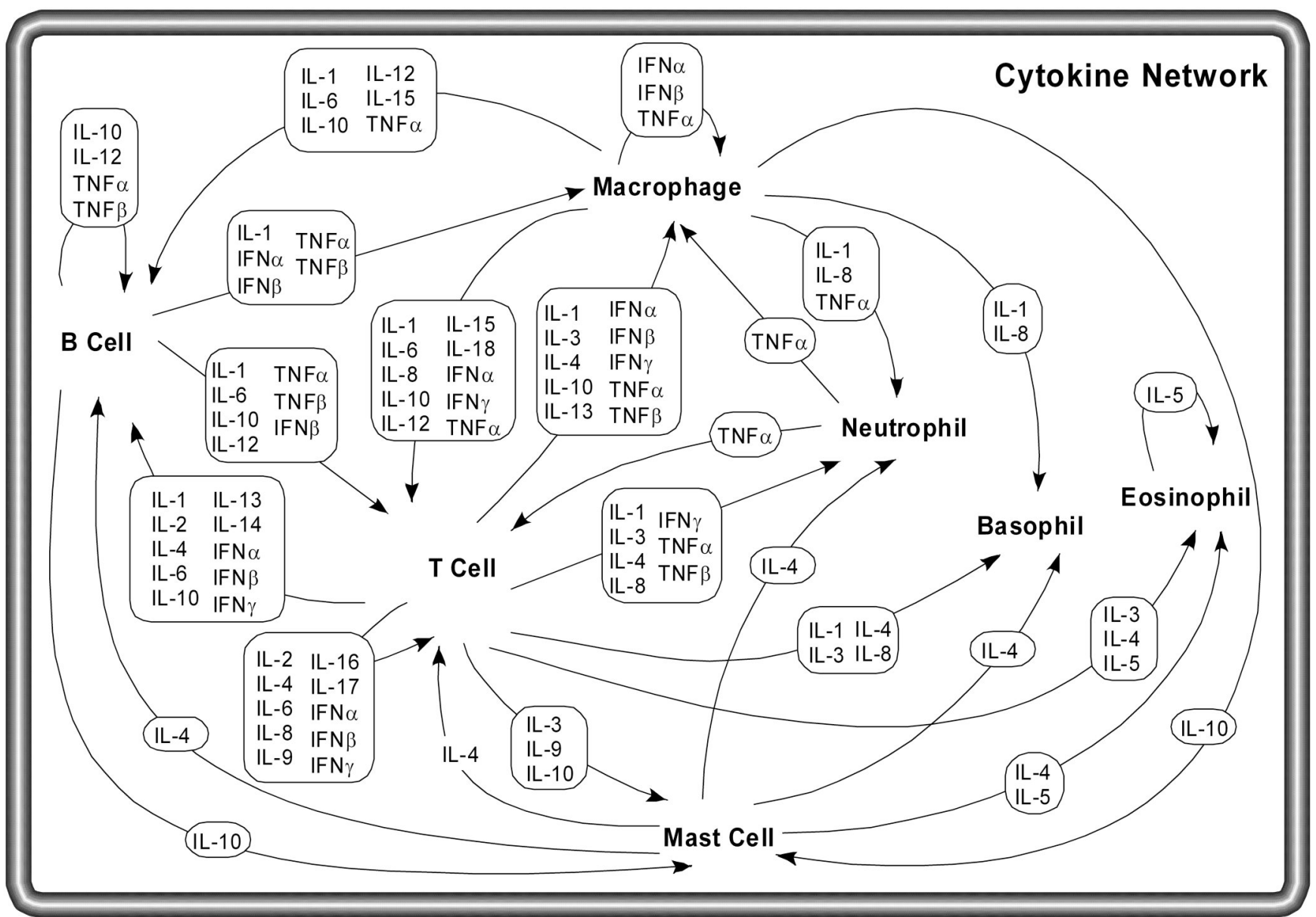

Figure 1.

Cytokine network. Several different cell types coordinate their efforts as part of the immune system, including B cells, T cells, macrophages, mast cells, neutrophils, basophils and eosinophils. Each of these cell types has a distinct role in the immune system, and communicates with other immune cells using secreted cytokines. Macrophages phagocytose foreign bodies and are antigen-presenting cells, using cytokines to stimulate specific antigen dependent responses by $\mathrm{B}$ and $\mathrm{T}$ cells and non-specific responses by other cell types. T cells secrete a variety of factors to coordinate and stimulate immune responses to specific antigen, such as the role of helper T cells in B cell activation in response to antigen. The proliferation and activation of eosinophils, neutrophils and basophils respond to cytokines as well. 
Table 1

Selected cytokines and their primary activities

\begin{tabular}{|c|c|c|}
\hline Cytokines & Principal Source & Primary Activity \\
\hline GM-CSF & Th cells & Growth and differentiation of monocytes and dendritic cells \\
\hline $\begin{array}{l}\text { IL- } 1 \alpha \\
\text { IL- } \beta\end{array}$ & $\begin{array}{l}\text { Macrophages and other antigen } \\
\text { presenting cells (APCs) }\end{array}$ & $\begin{array}{l}\text { Costimulation of APCs and T cells, inflammation and fever, acute phase } \\
\text { response, } \\
\text { hematopoiesis }\end{array}$ \\
\hline IL-2 & Activated Th1 cells, NK cells & Proliferation of B cells and activated T cells, NK functions \\
\hline IL-3 & Activated T cells & Growth of hematopoietic progenitor cells \\
\hline IL-4 & Activated T cells & $\begin{array}{l}\text { B cell proliferation, eosinophil and mast cell growth and function, IgE and } \\
\text { class II MHC } \\
\text { expression on B cells, inhibition of monokine production }\end{array}$ \\
\hline IL-5 & Th2 and mast cells & Eosinophil growth and function \\
\hline IL-6 & $\begin{array}{l}\text { Activated Th2 cells, APCs, other } \\
\text { somatic cells }\end{array}$ & $\begin{array}{l}\text { Acute phase response, B cell proliferation, thrombopoiesis, synergistic with } \\
\text { IL- } 1 \text { and TNF on } \\
\text { T cells }\end{array}$ \\
\hline IL-7 & Thymic and marrow stromal cells & $\mathrm{T}$ and $\mathrm{B}$ lymphopoiesis \\
\hline IL-8 & macrophages, somatic cells & Chemoattractant for neutrophils and T cells \\
\hline IL-9 & $\mathrm{T}$ cells & Hematopoietic and thymopoietic effects \\
\hline IL-10 & $\begin{array}{l}\text { Activated Th2 cells, CD8+ T and B } \\
\text { cells, macrophages }\end{array}$ & $\begin{array}{l}\text { Inhibits cytokine production, promotes B cell proliferation and antibody } \\
\text { production, } \\
\text { suppresses cellular immunity, mast cell growth }\end{array}$ \\
\hline IL-11 & Atromal cells & Synergistic hematopoietic and thrombopoietic effects \\
\hline IL-12 & B cells, macrophages & $\begin{array}{l}\text { Proliferation of NK cells, IFN production, promotes cell-mediated immune } \\
\text { functions }\end{array}$ \\
\hline IL-13 & Th2 cells & IL-4-like activities \\
\hline IL-18 & Macrophages & potent inducer of interferon-+ by T cells and NK cells \\
\hline $\begin{array}{l}\text { IFN- } \alpha \\
\text { IFN- } \beta\end{array}$ & $\begin{array}{l}\text { Macrophages, neutrophils and } \\
\text { some somatic cells }\end{array}$ & $\begin{array}{l}\text { Antiviral effects, induction of class I MHC on all somatic cells, activation of } \\
\text { NK cells and } \\
\text { macrophages }\end{array}$ \\
\hline IFN- $\gamma$ & Activated Th1 and NK cells & $\begin{array}{l}\text { Induces of class I MHC on all somatic cells, induces class II MHC on APCs } \\
\text { and somatic } \\
\text { cells, activates macrophages, neutrophils, NK cells, promotes cell-mediated } \\
\text { immunity, } \\
\text { antiviral effects }\end{array}$ \\
\hline MIP-1 $\alpha$ & Macrophages & Chemotaxis \\
\hline MIP-1 $\beta$ & Lymphocytes & Chemotaxis \\
\hline TGF- $\beta$ & T cells, monocytes & Chemotaxis, IL-1 synthesis, IgA synthesis, inhibit proliferation \\
\hline TNF- $\alpha$ & $\begin{array}{l}\text { macrophages, mast cells, NK } \\
\text { cells, sensory neurons }\end{array}$ & Cell death, inflammation, pain \\
\hline TNF- $\beta$ & Th1 and Tc cells & phagocytosis, NO production, cell death \\
\hline
\end{tabular}

